\title{
Experimental investigation on mass transfer for regeneration of liquid desiccant
}

\author{
S. Bouzenada ${ }^{1}$, T. Salmon ${ }^{2}$, L. Fraikin ${ }^{3}$, A. Kaabi ${ }^{4}$, A. Léonard ${ }^{5}$. \\ ${ }^{1,4}$ Department of Climatic Engineering, Faculty of Engineering Sciences, University Constantine \\ Corresponding Author: bouzenada_84@yahoo.fr (Saliha Bouzenada) \\ ${ }^{2,3,5}$ Department of Applied Chemistry, Laboratory of Chemical Engineering, University of Liege, Belgium
}

\begin{abstract}
Desiccants can be used in conjunction with solar energy to provide a viable alternative to traditional air conditioning techniques. Liquid desiccant regeneration was proved to be an effective method to extract the moisture from solution with a relatively less energy in order to regenerate the desiccant. An experimental study was carried out to analyze the effect of temperature for regeneration process using an injected air through the liquid desiccant solution (calcium chloride dihydrate) by a dryer. Many tests with different operating conditions such as air temperature, humidity ratio, air velocity and solution level are investigated in order to demonstrate that this salt is capable to absorb moisture and can be regenerated at a low temperature. Experimental results showed that the mass transfer is affected by the air conditions. Also, the vapour pressure difference between the air and liquid desiccant surface is the driving force of the mass transfer process. In this analysis it was also determined that the $\mathrm{CaCl}_{2} \cdot 2 \mathrm{H}_{2} \mathrm{O}$ could be regenerated at low temperature around 48 to $60^{\circ} \mathrm{C}$ hence the possibility of using the flat plate solar collectors for its regeneration and this salt can be used in a system (LDCS).
\end{abstract}

Key words: Liquid desiccant $\mathrm{CaCl}_{2} \cdot 2 \mathrm{H}_{2} \mathrm{O}$, Regeneration, Mass transfer, Solar energy.

\section{Introduction}

Growing demand for air conditioning in recent years has caused a significant increase in demand for primary energy resources. The traditional refrigeration cycles are driven by electricity or heat, which strongly increases the consumption of electricity and fossil energy. Furthermore, the traditional commercial, non natural working fluids, like CFC, HCFC and HFC result in both ozone depletion and global warming. "Liquid desiccant cooling systems" (LDCS) is one of the environmentallyfriendly techniques which may help alleviate the problem by utilizing solar energy and employing natural working fluids.

The liquid desiccant cooling system [1] shown in Fig.1 has been proposed as an alternative to the conventional vapour compression cooling systems to control air humidity, especially in hot and humid areas, due to its advantage in removing the latent load as well as its potential to remove a number of pollutants from the air stream.

The air is dehumidified by being in contact with concentrated solution. The solution is diluted during the dehumidification process, and needs to be regenerated before being reused. The desiccant is then regenerated, again in direct contact with an external air stream. The vapour pressure difference between the air and liquid desiccant is the potential for mass transfer. The regeneration of liquid desiccant can be driven by solar energy, waste heat or other low-grade heat source [2] [3].

Several works were done to investigate the regeneration of liquid Desiccant. Kabeel [4] studied the regeneration of liquid solution using cross-flow of air stream with flowing film of desiccant on the surface of a solar collector/regenerator. The forced air stream flows across the absorber removal moisture from the liquid solution. Calcium chloride $\left(\mathrm{CaCl}_{2}\right)$ solution with different concentrations flows upon the absorber area. The effect of the different parameters, on the evaporation rate and regeneration efficiency, was evaluated.

Also, an experimental study Kabeel [5] was carried out to evaluate the liquid desiccant system performance during dehumidification and humidification processes using an injected air through the liquid desiccant solution (calcium chloride). The experimental results allowed obtaining a mass transfer coefficient.

Xiong [6] conducted a study of new dehumidification system with two-stage liquid desiccants $\mathrm{CaCl}_{2}$ and $\mathrm{LiCl}$. The result showed that the $\mathrm{LiCl}$ solution provides better dehumidification capacity, but it is more difficult to regenerate. On the other hand, the $\mathrm{CaCl}_{2}$ solution is easier to be regenerated. The regeneration temperature affects the system performance significantly. Thus, a Calcium Chloride solution is recommended to be regenerated at $58{ }^{\circ} \mathrm{C}, 56{ }^{\circ} \mathrm{C}, 52{ }^{\circ} \mathrm{C}$ and $47^{\circ} \mathrm{C}$ while $\mathrm{LiCl}$ solution is regenerated at $72{ }^{\circ} \mathrm{C}, 68{ }^{\circ} \mathrm{C}, 64{ }^{\circ} \mathrm{C}$ and $60{ }^{\circ} \mathrm{C}$, respectively.

X.H. Liu [2] compared the mass transfer performance of two commonly used liquid desiccants, $\mathrm{LiBr}$ aqueous solution and $\mathrm{LiCl}$ aqueous solution. The experimental results showed, using the same desiccant mass flow rate, that the dehumidification performance of $\mathrm{LiCl}$ solution is better and the regeneration performance of $\mathrm{LiBr}$ solution is a little better or almost the same as that of $\mathrm{LiCl}$ solution.

An experimental investigation was carried out by Bassuoni [7] on using $\mathrm{CaCl}_{2}$ solution as desiccant. 
Performance of the system is evaluated using the mass transfer coefficient. It was found that increase of mass transfer coefficient for both dehumidifier/regenerator is observed by increasing both air and solution flow rates.

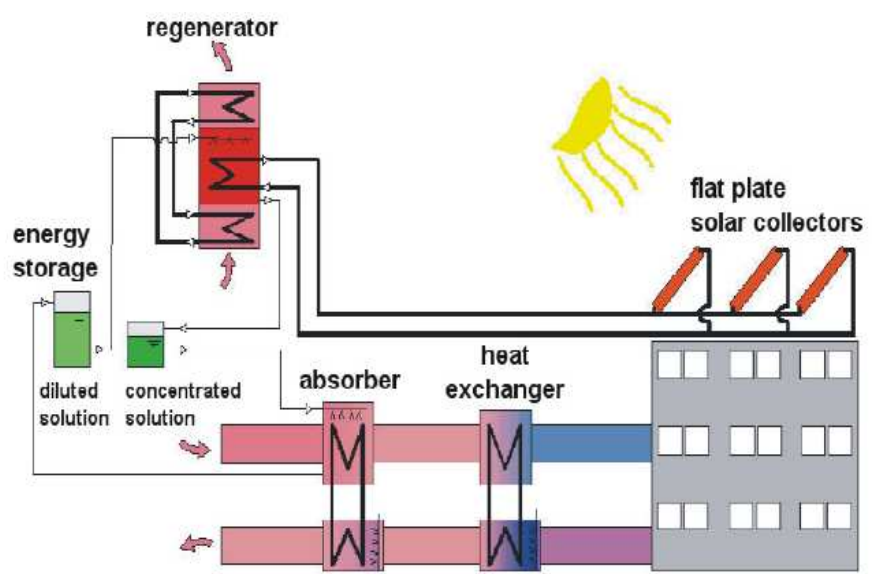

Fig.1. Schematic representation of a solar-driven (LDCS)

A performance test-bed for a cross-flow regenerator was established by X.L.Liu [8]. LiBr solution was used as the liquid desiccant. It was found that the increase of moisture removal rate is due to the increase in mass transfer coefficient between the air and desiccant with increasing air flow rate. High temperature of the desiccant within the regenerator can ensure the desiccant has higher surface vapour pressure and higher mass transfer potential.

The dehumidification process involves simultaneous heat and mass transfer and reliable transfer coefficients are required in order to analyze the system. The research presented by P. Gandhidasan [9] proposes the use of ANN based model in order to simulate the relationship between inlet and outlet parameters of the dehumidifier. Lithium chloride is chosen as the liquid desiccant. This study shows that liquid desiccant dehumidification system can be alternatively modelled.

A promising solar cooling method is through the use of a liquid desiccant system, where humidity is absorbed directly from the process air by direct contact with the desiccant. The desiccant is then regenerated, again in direct contact with an external air stream, by solar heat at relatively low temperatures [10]. K. Gommed presented a study to construct a prototype system based on the knowledge gained. $\mathrm{LiCl}$ water is employed as the working fluid.

This paper presents an experimental investigation in order to determine whether $\mathrm{CaCl}_{2} \cdot 2 \mathrm{H}_{2} \mathrm{O}$ is a suitable desiccant material for use in LDCS system, and can be regenerated at low temperature, so by solar energy. The experiments were carried out under different conditions for the temperature, the air flow rate, the humidity ratio and the exchange area to determine the characteristics of operation and air parameters effect on the mass transfer for the regeneration process. Therefore, the main objective of this work is to study and analyze the air temperature for regeneration and also, the capacity of this desiccant to absorb the moisture and to be regenerated at low temperature.

\section{Experimental procedure and equipment}

A discontinuous convective pilot scale dryer was used to make regeneration tests of $\mathrm{CaCl}_{2} \cdot 2 \mathrm{H}_{2} \mathrm{O}$ desiccant, as in Fig 2a. Two pieces of glass of $30 \mathrm{~cm}$ height are the core device of the setup. The plate containing the desiccant solution has a diameter of $16 \mathrm{~cm}$. The maximum mass that can support the apparatus is $1 \mathrm{~kg}$ and the maximum drying temperature is $180{ }^{\circ} \mathrm{C}$. The air superficial velocity of this cross flow system is in the range between 1 and $3 \mathrm{~m} / \mathrm{s}$. This dryer is connected to a computer to save measurements during the regeneration process, without any interruption. The experimental data are collected during regeneration process with a time interval of $10 \mathrm{~min}$ for each inlet condition. The regeneration temperature and the air flow are controlled.

In this work, the tests were done at a temperature fixed at $80{ }^{\circ} \mathrm{C}$. The total mass is measured by the balance incorporated into the experimental device. The ranges of air and desiccant parameters are shown in Table 1.

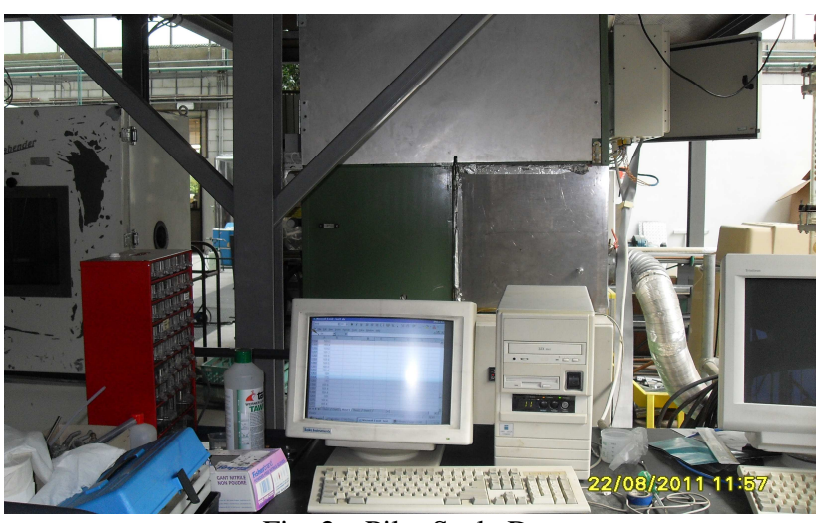

Fig. 2a. Pilot Scale Dryer

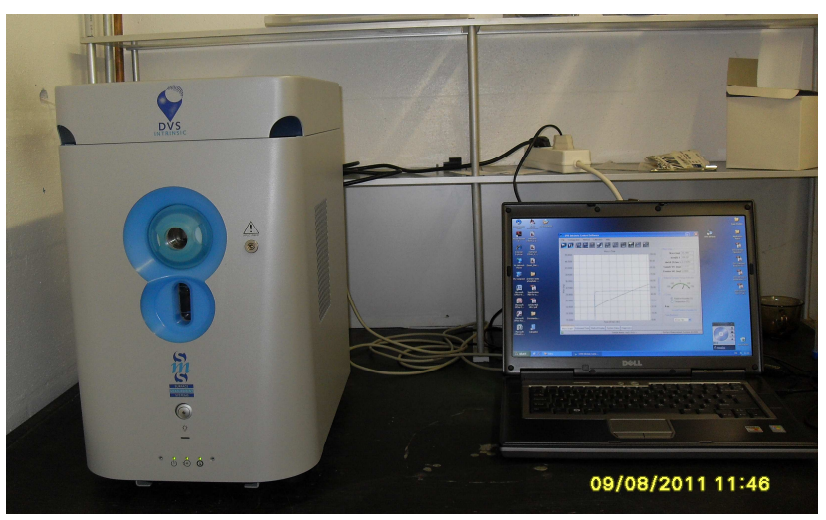

Fig. 2b. DVS

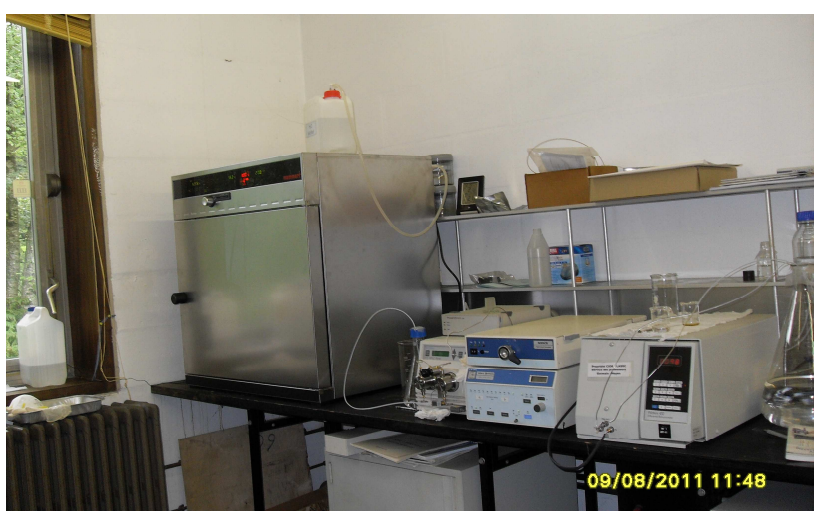

Fig. 2c. Conditioning Drying Oven 
The liquid desiccant is placed in the central part closed in large convective dryer, in which cross-flowing air and desiccant exchange heat and moisture. The solution has been changed of liquid state to solid state.

Table 1 - Experimental conditions - Pilot Scale Dryer

\begin{tabular}{|l|l|l|}
\hline \multicolumn{1}{|c|}{ Parameter } & \multicolumn{1}{c|}{ Range } & \multicolumn{1}{c|}{ Accuracy } \\
\hline Air temperature & $80^{\circ} \mathrm{C}$ & $+0,1^{\circ} \mathrm{C}$ \\
\hline Air velocity & $1-5 \mathrm{~m} / \mathrm{s}$ & $+0,1 \mathrm{~m} / \mathrm{s}$ \\
\hline Mass of salt & $7,5-36,23 \mathrm{~g}$ & $+0,1 \mathrm{~g}$ \\
\hline
\end{tabular}

In order to compare the results several tests were done in second equipment called "DVS, Dynamic vapor sorption" Fig.2b, initially dedicated to the determination of water adsorption-desorption isotherm. However by fixing the temperature and humidity, it is possible to use it in a drying mode for small samples (some $\mathrm{mg}$ ), under controlled gas flow. The ranges of air and desiccant parameters are shown in Table 2.

Table 2 - Experimental measurements: DVS

\begin{tabular}{|l|l|l|}
\hline \multicolumn{1}{|c|}{ Parameter } & \multicolumn{1}{c|}{ Range } & \multicolumn{1}{c|}{ Accuracy } \\
\hline $\begin{array}{l}\text { Air temperature for } \\
\text { regeneration }\end{array}$ & $20-80{ }^{\circ} \mathrm{C}$ & $+0,1{ }^{\circ} \mathrm{C}$ \\
\hline Relative humidity & $0-95 \%$ & \\
\hline $\begin{array}{l}\text { Mass of liquid salt } \\
\text { And dry salt }\end{array}$ & $\begin{array}{l}\text { from } 7,91 \text { to } \\
45,31 \mathrm{mg}\end{array}$ & $+0,001 \mathrm{~g}$ \\
\hline $\begin{array}{l}\text { Air temperature for } \\
\text { absorption }\end{array}$ & $20-32{ }^{\circ} \mathrm{C}$ & \\
\hline
\end{tabular}

The third equipment is a "Conditioning Drying Oven" Fig. 2c, and the plate used has a diameter of 9 and $16 \mathrm{~cm}$. The parameters used are shown in Table 3.

Table 3 - Experimental measurements: Conditioning Drying Oven

\begin{tabular}{|l|l|l|}
\hline \multicolumn{1}{|c|}{ Parameter } & \multicolumn{1}{|c|}{ Range } & Accuracy \\
\hline $\begin{array}{l}\text { Air temperature for } \\
\text { regeneration }\end{array}$ & $40-60-80{ }^{\circ} \mathrm{C}$ & $+0,1^{\circ} \mathrm{C}$ \\
\hline Relative humidity & $0-95 \%$ & \\
\hline Mass of dry salt & from 0,1 to $20 \mathrm{~g}$ & $+0,001 \mathrm{~g}$ \\
\hline $\begin{array}{l}\text { Air temperature for } \\
\text { absorption }\end{array}$ & $20-28{ }^{\circ} \mathrm{C}$ & \\
\hline
\end{tabular}

Several experimental measurements were made in a relatively large range of operating conditions which can be adopted in order to make the comparison of results. Only one parameter is varied for each test and the others remain the same so the experimental results can be used directly to compare the effects of parameters on regeneration process of different tests.

Before starting the process of regeneration salt, the first experimental study concerned the process of absorption. Different climatic conditions were imposed for each series of measurements and the phenomenon of absorption was observed. During the absorption phenomena, the salt undergoes a series of transformations. The $\mathrm{CaCl}_{2} \cdot 2 \mathrm{H}_{2} \mathrm{O}$ which is initially completely dry and solid in the beginning, changes in appearance after six hours $(6 \mathrm{~h})$, as the moisture absorbed changes the colour and the salt is defragmented. The final mixture becomes fluid.

After each absorption test was complete, the final desiccant was found in viscous liquid solution form. The solution is diluted during the dehumidification process, and needs to be regenerated before being reused. These tests consist of measuring the mass during the regeneration and absorption process with the variation of parameters.

The regeneration process, similar to drying, is driven by a mass transfer potential, being the difference in vapour pressure between the desiccant interface $P_{v}$ and the air $\mathrm{P}_{\mathrm{a}}$. The vapour pressure at the desiccant interface depends on the salt solution temperature and its water activity. Water activity reflects the hygroscopic character of a product and its ability to fix moisture. It can be determined through the measurement of adsorptiondesorption isotherms. For desiccant solutions, water activity decreases with increasing salt concentration, i.e. the vapour pressure at its surface will also decrease.

So, the flow of evaporated water during regeneration is given by equation (1) as a function of convective mass transfer coefficient $\mathrm{K}_{\mathrm{m}}$, $\left(\mathrm{kg}\right.$ eau $/ \mathrm{m}^{2}$.s.pa), exchange area $\left(\mathrm{m}^{2}\right)$ and driving potential. In this expression $\mathrm{P}_{\mathrm{v}}(\mathrm{Pa})$ depends on the product water activity $\mathrm{a}_{\mathrm{w}}$, and vapour pressure difference between the air and liquid desiccant is the driving force of the mass transfer process.

$$
\begin{aligned}
& \mathrm{m}_{\mathrm{e}}=\mathrm{A} \cdot \mathrm{K}_{\mathrm{m}}\left[\mathrm{P}_{\mathrm{sat}}-\mathrm{P}_{\mathrm{v}}\right] \\
& \mathrm{a}_{\mathrm{w}}=\left(\mathrm{P}_{\mathrm{v}}\right) /\left(\mathrm{P}_{\mathrm{sat}}\right)
\end{aligned}
$$

\section{Results and discussion}

Experimental tests have been conducted with different parameters to investigate the regeneration process for the liquid desiccant in direct contact with the air blown and its ability to absorb moisture and also its capacity to be regenerated at low temperature. Different categories are parametrically investigated in this study.

The regeneration tests were run until the desiccant was approximately dry because it was necessary for the desiccant to be as dry as possible for the sorption tests. This study is mainly focused on the effect of regeneration temperature and humidity rate on mass transfer between air and desiccant.

Fig. 3 shows the regeneration results obtained using the Pilot Scale Dryer at $80^{\circ} \mathrm{C}$. This Fig. clearly shows that the $\mathrm{CaCl}_{2} \cdot 2 \mathrm{H}_{2} \mathrm{O}$ desiccant is able to release moisture. Then the concentration of the solution increases but the vapour pressure at the surface of the salt decreases, due to the decrease of water activity. So the desiccant is regenerated and regains its hygroscopic characteristic. These observations and conclusion for results agree with those published in the literature by Bassuoni [7] and X.H.Liu [8].

The impact of the initial amount of salt was assessed using the same apparatus Pilot Scale Dryer at $80^{\circ} \mathrm{C}$. Fig 4 shows the evolution of the regeneration process as a function time for the same temperature and exchange area but for two initial masses of solution. The 
regeneration duration is shorter when the quantity of desiccant used decreases.

Some experiments were also done in a "Conditioning Drying Oven". In this equipment the control of humidity is easier but there is no forced convective flow amount the product. Fig. 5 shows the two processes on the same graph absorption and regeneration.

The impact of the regeneration temperature is presented in Fig. 6 for two identical masses of diluted $\mathrm{CaCl}_{2} \cdot 2 \mathrm{H}_{2} \mathrm{O}$ placed on an identical surface. It was observed that the moisture removal rate increases with increasing temperature.

From this figure, the duration of the regeneration process can also be obtained as a function of the regeneration temperature. It can be concluded that a higher temperature gives a higher potential for mass transfer and a shorter duration of regeneration. This analysis is compared to works reported in the literature; the similar observation presented by Bassuoni [7] and X.H.Liu [8].

The effect of air humidity on regeneration process was studied using the same equipment "Conditioning Drying Oven". Fig 7 illustrates the important role of air humidity. Indeed, for the same temperature and desiccant concentration, the regeneration process becomes longer at higher relative humidity. Moreover, the regeneration is not complete as the final mass at equilibrium is higher at high humidity. This shows the impact of air humidity on the mass transfer potential on the one hand, and on the equilibrium moisture content of salt solution, on the other hand.

So, an increase in air inlet humidity ratio caused a decrease in the mass transfer potential between the air and desiccant. In addition, the findings are compared to the work presented in the literature by X.H.Liu [8], it's the same observation for air humidity.

Fig. 8 shows the impact of the quantity of salt on the regeneration process, as already observed in the "Conditioning Drying Oven".

Some tests were also done in convective conditions but at a small scale in the "DVS". Fig. 9 shows that this desiccant is easy to be regenerated with an air at low temperature, i.e. $40^{\circ} \mathrm{C}$. This heat level can be obtained by flat plate solar collectors. This observation is in accordance with other conclusions presented in the literature which showed that this desiccant can be regenerated at a temperature of $47-58{ }^{\circ} \mathrm{C}$.

Fig. 10 shows the possibility to study 'cycling' in the DVS by following successive phases of state change for the desiccant: regeneration, humidity absorption, and regeneration. The results clearly show that the $\mathrm{CaCl}_{2} \cdot 2 \mathrm{H}_{2} \mathrm{O}$ is a desiccant able to absorb moisture from the air and also that it can be regenerated at low temperature during successive phases of absorption and regeneration.

The dry salt has absorbed moisture from the air to $95 \%$ with a minimum temperature of $20^{\circ} \mathrm{C}$. After, the solution obtained is in liquid form and was dried at $80^{\circ} \mathrm{C}$ with a minimum relative humidity of $20 \%$.

Fig. 11 shows the reproducibility of the regeneration process: for the same climatic conditions and same plate area, the two curves are superimposed.
Increasing solution concentration decreases the partial vapour pressure on the desiccant surface. This variation is shown in Fig. 12 and Fig. 13.

As for regeneration process, during the absorption, the humidity rate influences the mass. Fig 14 shows the relationship between the mass and the relative humidity.

Fig 15 and Fig.16 show the variation of temperature and humidity during the air dehumidification, so the relative humidity decreases and the temperature increases.

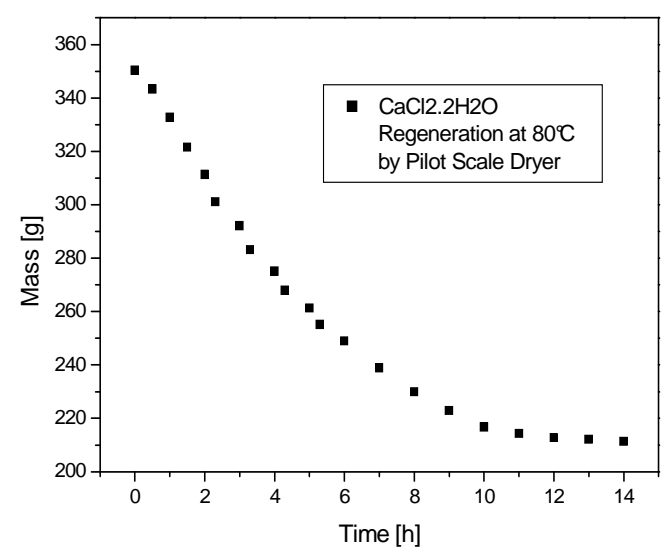

Fig.3. Regeneration process of $\mathrm{CaCl}_{2} \cdot 2 \mathrm{H}_{2} \mathrm{O}$ Test by Pilot Scale Dryer

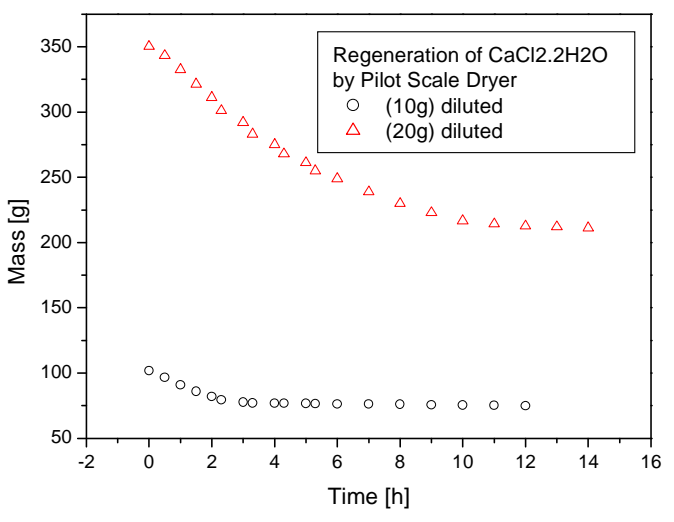

Fig.4. Effect of quantity of salt on regeneration Test by Pilot Scale Dryer

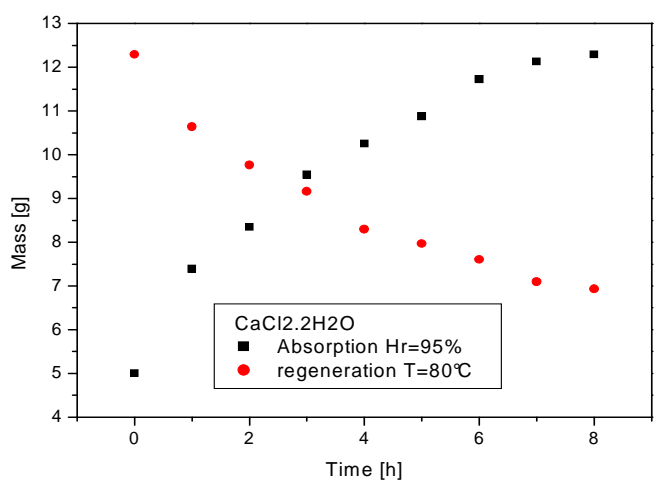

Fig.5. Absorption and regeneration process Test by Conditioning Drying Oven 


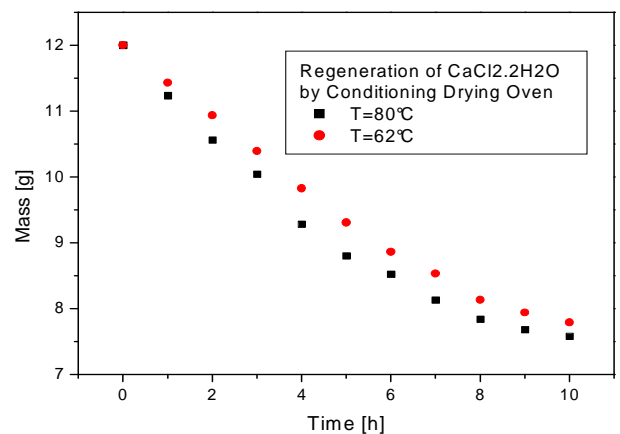

Fig.6. Effect of temperature on regeneration process Test by Conditioning Drying Oven

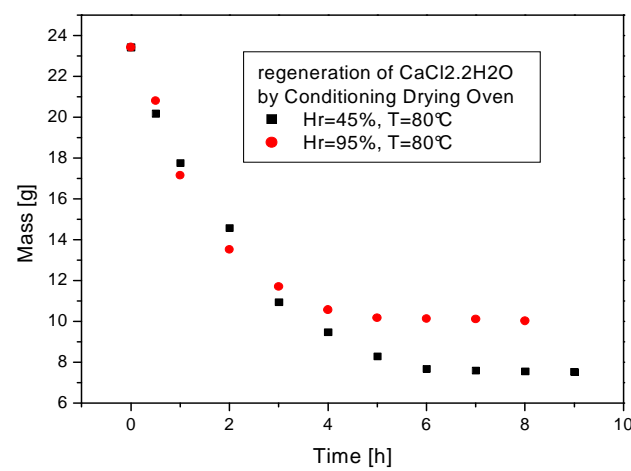

Fig.7. Effect of humidity on regeneration process Test by Conditioning Drying Oven

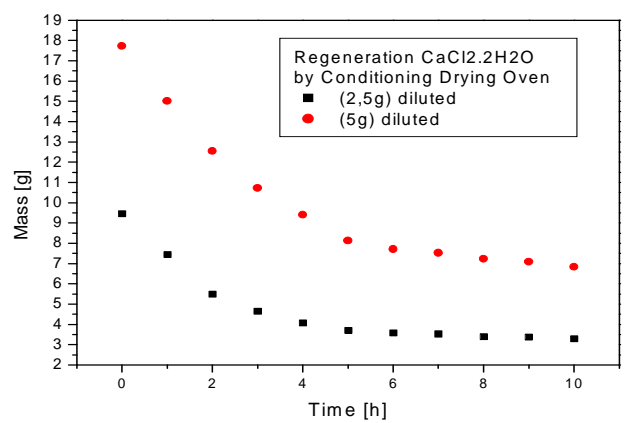

Fig.8. Validation: regeneration as a function of quantity Test by Conditioning Drying Oven

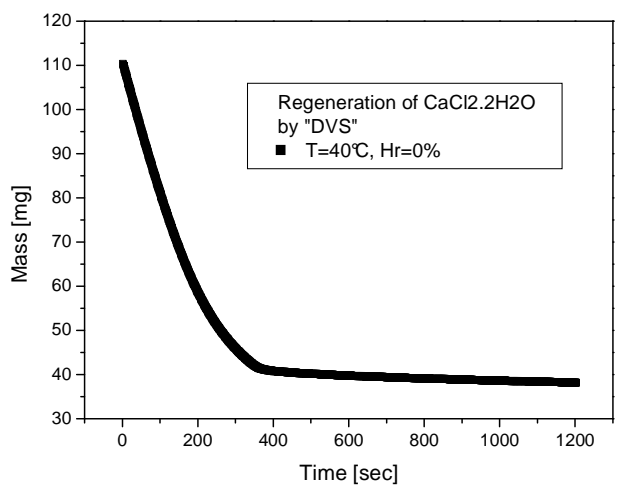

Fig.9. Regeneration of the desiccant at low temperature Test by DVS

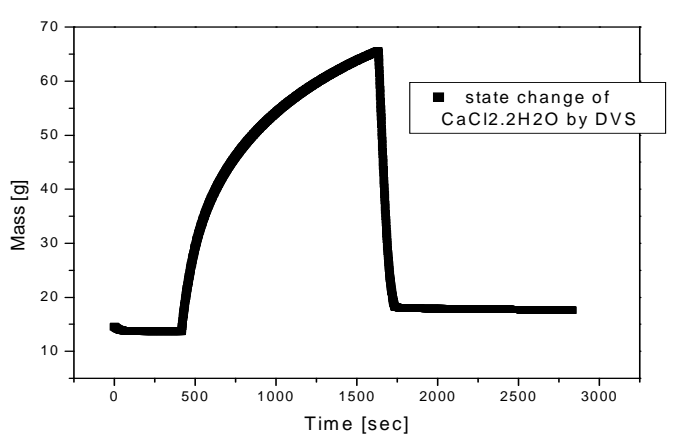

Fig. 10. Three phases of change of state of desiccant Test by DVS

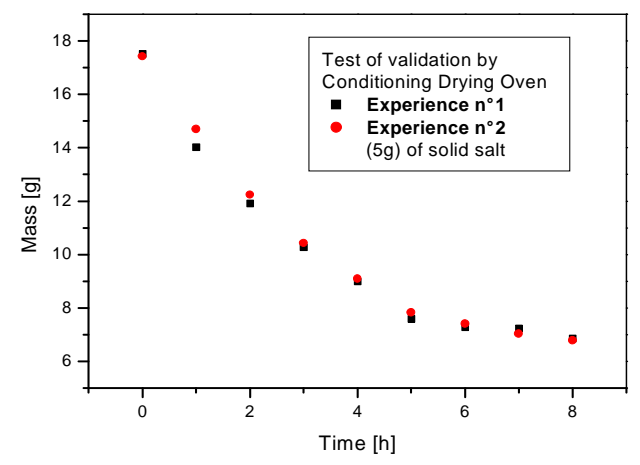

Fig.11. Validation of regeneration Test by Conditioning Drying Oven

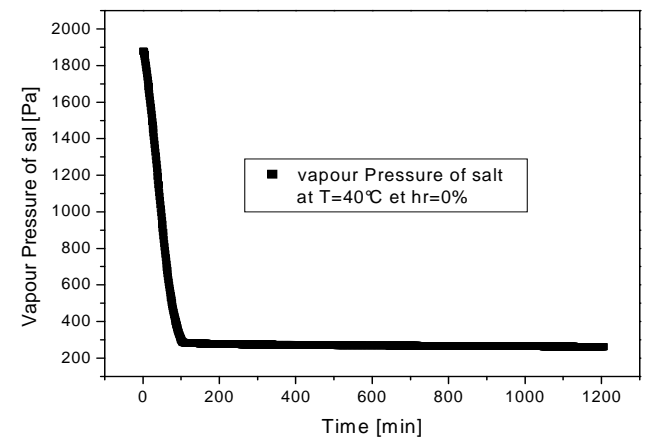

Fig. 12. Variation of pressure of regeneration process Test by DVS

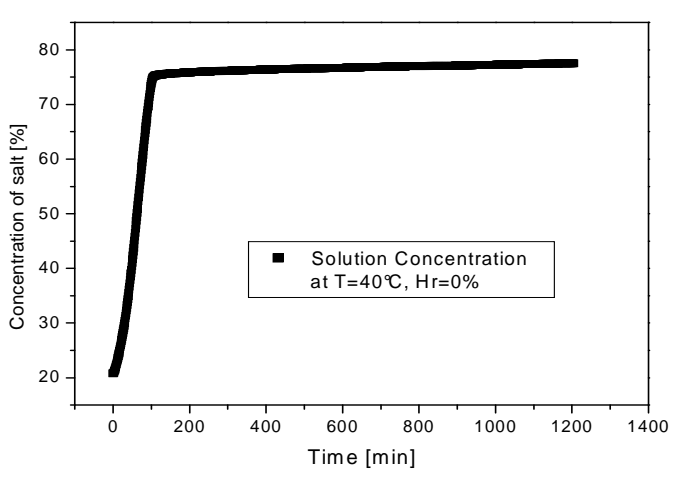

Fig. 13. Variation of concentration of regeneration process Test by DVS 


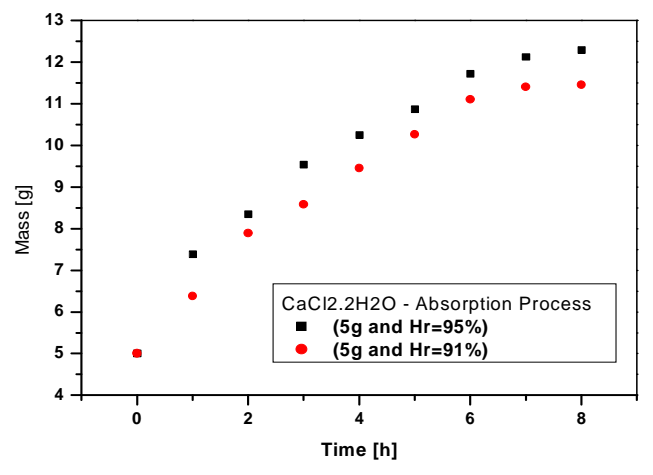

Fig. 14. The effect of humidity on absorption process Test by Conditioning Drying Oven

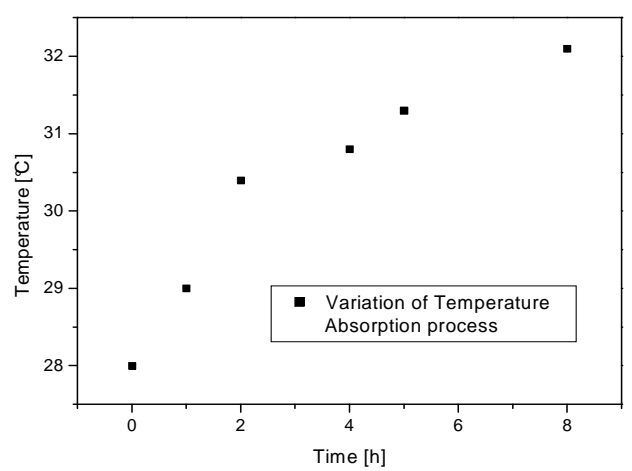

Fig. 15. Variation of temperature during absorption process Test by Conditioning Drying Oven

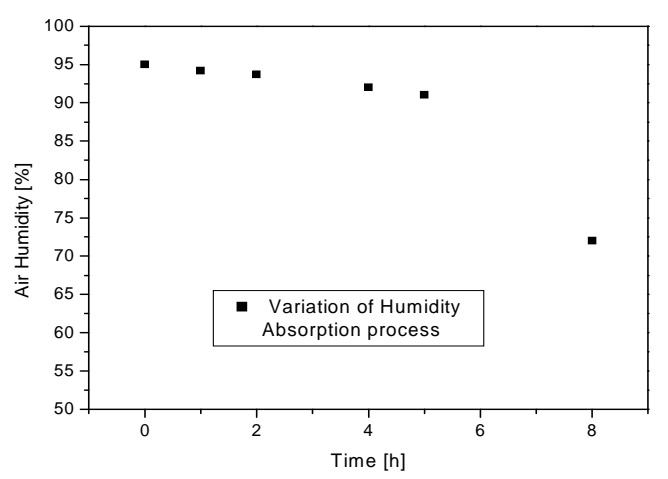

Fig. 16. Variation of humidity during absorption process Test by Conditioning Drying Oven

\section{Conclusions}

Experimental investigation on solution regeneration process has been carried out. $\mathrm{CaCl}_{2} \cdot 2 \mathrm{H}_{2} \mathrm{O}$ aqueous solution is used as the desiccant in this study. This study is mainly focused on the mass transfer. This work presents the effect of air temperature and humidity on mass transfer between the air and desiccant put in direct contact. The objective of regeneration process is to transfer the water vapor from the desiccant solution to air stream. From this investigation the following conclusions were obtained:
- This desiccant is able to be regenerated in a temperature range of $40-60^{\circ} \mathrm{C}$.

- During the regeneration process the concentration of the solution increases but the vapor pressure at the surface of the desiccant decreases.

- In addition, an increase of the air temperature causes a shorter duration of regeneration process.

- The advantage of using liquid desiccant $\mathrm{CaCl}_{2} \cdot 2 \mathrm{H}_{2} \mathrm{O}$ is that this desiccant is able to be regenerated and that it is a natural working fluid which does not harm the environment.

- This salt has an easy regeneration at low temperature. Therefore this desiccant can be used in a system (LDCS) "Liquid desiccant cooling systems" and regenerated by solar energy.

\section{References}

[1] Manuel Conde-Petit, Dr Sc Tech ETHZ. Liquid desiccantbased air-conditioning systems - LDACS. 1st European Conference on Polygeneration. Tarragona (Spain), 16-17 October 2007.

[2] X.H. Liu , X.Q. Yi, Y. Jiang. Mass transfer performance comparison of two commonly used liquid desiccants: $\mathrm{LiBr}$ and $\mathrm{LiCl}$ aqueous solutions. Energy Conversion and Management 52 (2011) 180-190.

[3] Donggen Peng, Xiaosong Zhang. Modeling and performance analysis of solar air pre-treatment collector/regenerator using liquid desiccant. Renewable Energy xxx (2008) 1-7.

[4] Kabeel AE. Augmentation of the performance of solar regenerator of open absorption cooling system. Renewable Energy 2005;30:327-38.

[5] Kabeel. A.E. Dehumidification and humidification process of desiccant solution by air injection. Energy 35 (2010) $5192-5201$

[6] Z.Q. Xiong, Y.J. Dai , R.Z. Wang. Development of a novel two-stage liquid desiccant dehumidification system assisted by $\mathrm{CaCl}_{2}$ solution using exergy analysis method. Applied Energy 87 (2010) 1495-1504.

[7] M.M. Bassuoni. An experimental study of structured packing dehumidifier/regenerator operating with liquid desiccant. Energy 36 (2011) 2628-2638.

[8] X.H. Liu, Y. Jiang, X.M. Chang, X.Q. Yi. Experimental investigation of the heat and mass transfer between air and liquid desiccant in a cross-flow regenerator. Renewable Energy 32 (2007) 1623-1636.

[9] Gandhidasan. P, Mohandes. M.A. Artificial neural network analysis of liquid desiccant dehumidification system. Energy 36 (2011) 1180-1186.

[10] K. Gommed, G. Grossman. Experimental investigation of a liquid desiccant system for solar cooling and dehumidification. Solar Energy 81 (2007) 131-138. 